\title{
Optimal Control of Lipid Extraction Model on Microalgae Using Linear Quadratic Regulator (LQR) and Pontryagin Maximum Principle (PMP) Methods
}

\author{
Mardlijah*, Nur Ilmayasinta, Lukman Hanafi and Suharmadi Sanjaya \\ Department of Mathematics, Faculty of Mathematics, Computation, and Data Science \\ Institut Teknologi Sepuluh Nopember Surabaya, 60111 ITS Surabaya, Indonesia \\ ${ }^{*}$ Corresponding author: mardlijah@matematika.its.ac.id
}

Article history

Received: 22 August 2018

Received in revised form: 6 December 2018

Accepted: 17 December 2018

Published on line: 31 December 2018

\begin{abstract}
Algae are good plants as raw materials for biodiesel. Chlorella Vulgaris is one of the most economical algae to produce biodiesel since it is rich in carbohydrates, require no special care, and easy to grow. Algae oil for biodiesel production is obtained through fairly long processes, one of which is the lipid extraction. Mathematical model can be used to obtain optimal results. The optimal control theory itself is concerned with the analysis of controlled dynamic systems, in which a system is directed from configurations given to some desire target by minimizing or maximizing some criteria. In this study, LQR formulation has the advantages of easy to analyze and implementation. In comparison, optimum control is performed using the PMP method, to obtain the best control of the dynamic system from the initial state to the end, i.e by maximizing the objective function. This method is a better method than the LQR method. Optimal control is performed in order to optimize the yield of lipid concentration in the solvent flow $\left(C_{s}\right)$, in the microalgae particles $\left(C_{p}\right)$, and minimizing the volume of solvent $(v)$. From the simulation, it is found that the PMP method is more optimal in this system compared to the LQR method.
\end{abstract}

Keywords Microalgae; optimal control; linear quadratic regulator; pontryagin maximum principle.

Mathematics Subject Classification 46N60, 92B99.

\section{Introduction}

Biodiesel is an oil fuel made of renewable materials like plants and animals being used as an alternative to fossil fuels. Biodiesel has a 10-15 cetane number, higher than diesel, so the combustion process is faster, the engine becomes smoother, and not noisy [1,2]. Plant species that can be used for biodiesel feedstock are palm oil, soybean, jatropha curcas, and some potentially good plants as the biodiesel feedstock, i.e. microalgae. The superiority of microalgae compared to other vegetable materials is in the process of extracting the oil that is done without milling and directly extracted with the help of solvent [3]. Microalgae are water plants that 
can be grouped into 2 groups of macroalgae and microalgae. Indonesia have 782 species of microalgae scattered throughout the territorial waters of Indonesia. Microalgae are autotrophs that can photosynthesize and thus require sufficient sunlight and carbon dioxide [4]. Choosing microalgae as the basic ingredient of biodiesel is a good alternative based on the amount of production. It is estimated that microalgae are capable of producing 200 times more biodiesel than oil-producing plants (jatropha oil and palm oil) [5].

Chlorella Vulgaris microalgae are recommended for industrial ingredients. In addition to a large number microalgae in Indonesian waters, this type of microalgae has been widely cultivated in bulk. Research on microalgae as an alternative energy source has been much done like the research done by $[2,4-6]$. Processing microalgae oil into biodiesel requires a fairly long process. One of the important steps is the extraction of lipids. Extraction is the process of separating components from solids with the help of solvents. Liquid-solid extraction or leaching is the transfer of dissolved components diffusion from solids into the solvent, which uses CXM (CO2-Expanded Methanol) solvent in this study. In the extraction process, there occurs the process of lipid mass transfer contained in Chlorella Vulgaris using Soxhlet tool that uses repetitive filtering and heating. The process of lipid mass transfer from this microalgae will then be formed in a differential equation as a mathematical model.

In this research the mathematical model is used to predict the extracted lipid results for subsequent use as the main ingredient of biodiesel production and optimal control is performed by adjusting the volume of solvent to produce maximum lipid extraction. To obtain the maximum lipid extraction, optimal control in accordance with the mathematical model obtained is required. Therefore in this study LQR (Linear Quadratic Regulator) is chosen because LQR is able to overcome big disturbance in stability system without reducing working performance and can overcome disturbance that accured previously. The LQR method is expected to produce a better response than the response before the optimal control is performed.

\section{Mathematical Model}

This chapter describes the mathematical model of microalgae lipid extraction and analysis systems, including the analysis of stability, control, and observability.

\subsection{Mathematical Models of Microalgae Lipid Extraction}

The research by [7] with data obtained from [8] provides the mathematical model for the process of lipid extraction [7]. Subsystem (1) describes the balance process that occurs in the extraction process that describes the axial convection events, axial dispersion, radial disperse, mass transfer from the solid surface to the flow of solvent and accumulation:

$$
\frac{d C_{s}}{d t}=-\frac{\left(1-\varepsilon_{v}\right)}{\varepsilon} \frac{d C_{v}}{d t}-\frac{S}{\rho \varepsilon V} C_{s} .
$$

Subsystem (2) gives the process of mass balance on microalgae particles by considering the process of mass transfer of lipids by adsorption:

$$
\frac{d C_{v}}{d t}=-\frac{k_{f} a\left(C_{v}-C_{s a t}\right)}{V\left(1-\varepsilon_{v}\right)}-\frac{d C_{l}}{d t} .
$$


Subsystem (3) gives the absorption of CXM solvent. Adsorbtion occurs when the solvent is bound to the lipid in the microalgae and subsequently there is a reversible uptake process to exit from the solid phase (solid) of the microalgae particles. It is assumed that the lipid has a homogeneous surface, the extraction process occurs in isotherms and the adsorption rate is different from the desorption rate:

$$
\frac{d C_{l}}{d t}=k_{a} C_{p}-k_{d} C_{l} .
$$

Table 1: Description of the Variables and Parameters

\begin{tabular}{|c|c|c|}
\hline Symbol & Description & Unit \\
\hline$C_{t}$ & Lipid concentration on the surface of particle & $\mathrm{kg} / \mathrm{m}^{3}$ \\
$C_{p}$ & Lipid concentration in microalgae particles & $\mathrm{kg} / \mathrm{m}^{3}$ \\
$C_{s}$ & Lipid concentration in the flow of solvent & $\mathrm{kg} / \mathrm{m}^{3}$ \\
$K_{a}$ & Kinetic constant adsorption & $1 / \mathrm{s}$ \\
$K_{d}$ & Kinetic constant desorption & $1 / \mathrm{s}$ \\
$K_{f}$ & Mass transfer coefficient & $\mathrm{m} / \mathrm{s}$ \\
$C_{s a t}^{*}$ & Lipid concentration in balance & $\mathrm{kg} / \mathrm{m}^{3}$ \\
$\varepsilon_{P}$ & Porosity of microalgae particles & - \\
$S$ & Solvent flow rate & $\mathrm{kg} / \mathrm{s}$ \\
$a$ & Surface area of microalgae particles $\left(4 \pi r^{2}\right)$ & $\mathrm{m}{ }^{2}$ \\
$\rho$ & Mass solvent type & $\mathrm{kg} / \mathrm{m}^{3}$ \\
$V$ & Volume of solvent & $\mathrm{m}^{3}$ \\
\hline
\end{tabular}

\subsection{System Analysis}

\subsubsection{Analysis of System Stability}

Equations (1) - (3) if expressed in terms of the state space matrix become:

$$
\left[\begin{array}{c}
\frac{d C_{s}}{d t} \\
\frac{d C_{p}}{d t} \\
\frac{d C_{l}}{d t}
\end{array}\right]=\left[\begin{array}{ccc}
-\frac{S}{\rho \varepsilon V} & -\frac{1-\varepsilon_{p}}{\varepsilon}\left(-\frac{k_{f} a}{V\left(1-\varepsilon_{p}\right)}-k_{a}\right) & -\frac{1-\varepsilon_{p}}{\varepsilon} k_{d} \\
0 & -\frac{k_{f} a}{V\left(1-\varepsilon_{p}\right)}-k_{a} & k_{d} \\
0 & k_{a}
\end{array}\right]\left[\begin{array}{c}
C_{s} \\
C_{p} \\
C_{l}
\end{array}\right]+\left[\begin{array}{c}
0 \\
\frac{k_{f} a C_{s a t}^{*}}{V\left(1-\varepsilon_{p}\right)} \\
0
\end{array}\right] .
$$


Next, we will look for the eigenvalues of the above system given by

$$
\left(\lambda+\frac{S}{\rho \varepsilon V}\right)\left(\lambda+\left(\frac{k_{f} a}{V\left(1-\varepsilon_{p}\right)}+k_{a}\right)\right)\left(\lambda+k_{d}\right)-k_{a} k_{d}\left(\lambda+\frac{S}{\rho \varepsilon V}\right)=0 .
$$

Based on the stability theorem [9] the system is said to be stable at the point of origin $\bar{x}=0$ when and only if $\operatorname{Re}\left(\lambda_{i}\right) \leq 0$ for all $i=1, \ldots, k$ and for all $\left(\lambda_{i}\right)$ with $\operatorname{Re}\left(\lambda_{i}\right)=0$ the multiplicity of algebra equals its geometric multiplicity. Using the Routh-Hurwitz formula, it can be written in Table 2.

Table 2: Routh-Hurwitz Formula

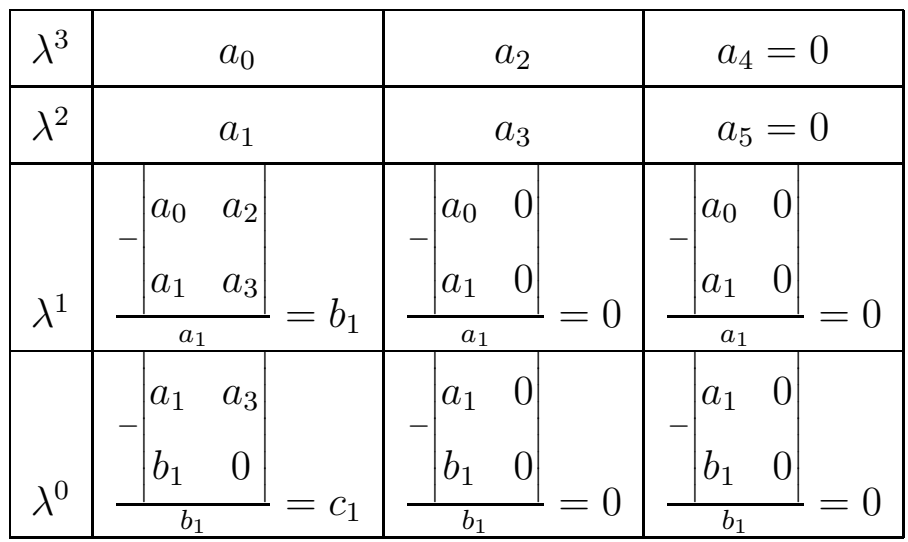

Given the value of the parameter to be used in the extraction process as in Table 3

Table 3: Parameter Value of Microalgae Lipid Extraction Model

\begin{tabular}{|c|c|}
\hline Parameter & Value \\
\hline$k_{a}$ & $0.0000021 / \mathrm{s}$ \\
\hline$k_{d}$ & $0.0000011 / \mathrm{s}$ \\
\hline$k_{f}$ & $1.72737 \mathrm{~m} / \mathrm{s}$ \\
\hline$a$ & $1.256 \times 10^{-11} \mathrm{~m}^{2}$ \\
\hline$C_{s a t}^{*}$ & 9.25 \\
\hline$V$ & $9 \times 10^{-5} \mathrm{~m}^{3}$ \\
\hline$\varepsilon_{p}$ & 0.3 \\
\hline$S$ & $5 \times 10^{-5} \mathrm{~kg} / \mathrm{s}$ \\
\hline$\rho$ & $74.79195 \mathrm{~kg} / \mathrm{m}^{3}$ \\
\hline
\end{tabular}

Due to parameter values $S, \rho, \varepsilon, V, k_{f}, a, k_{a}$, and $k_{d}$ all are positive. Thus, it is clear that $a_{1}, a_{2}, a_{3}, a_{4}>0$. The value of $b_{1}$ is calculated as $b_{1}=\frac{a_{1} a_{2}-a_{0} a_{3}}{a_{1}}$. Which $a_{0}=1, a_{1}=$ 
$2.48 \times 10^{-2}, a_{2}=1.68 \times 10^{-7}$, and $a_{3}=1.93 \times 10^{-13}$, gives $b_{1}=1.68 \times 10^{-7}$. The value of $c_{1}$ is calculated as $c_{1}=\frac{b_{1} a_{3}-b_{2} a_{1}}{b_{1}}$. Which, $a_{4}=0, a_{5}=0$, and $b_{2}=0$, then value $c_{1}>0$ if $b_{1} a_{3}>b_{2} a_{1}$. Since the value $b_{2}>0$, it is clear that $b_{1} a_{3}>b_{2} a_{1}$. So it can be concluded that $c_{1}>0$. Based on the stability theorem [9] and the values $a_{1}>0, b>0 c_{1}>0$, the system above is a stable system.

\subsubsection{Analysis of System Control}

Analysis of the control system is crucial because if the system is not controlled, the solution to optimal control problems may not be obtained. Consider the linear $n$-time invariant-time linear system presented by the equation:

$$
\begin{aligned}
& \dot{x}=A x+B y . \\
& \dot{y}=C x+D y .
\end{aligned}
$$

Definition 1 [10] The linear system is said to be controlled if for any circumstance $x(0)=x_{0}$ there are input $u(t)$ that is not restricted to the state of $x_{0}$ to any end state $x\left(t_{1}\right)=x_{1}$ with end time $t_{1}$ up.

Sufficient requirement for a linear system to be controlled is the matrix

$$
M_{c}=\left[\begin{array}{lllll}
B & A B & A^{2} B & \cdots & A^{n-1} B
\end{array}\right]
$$

have a rank equal to $n$. Based on the value of parameters that have been obtained, we have:

$$
A=\left[\begin{array}{ccc}
-1.026 \times 10^{-11} & 5.0671 \times 10^{-6} & -2.3364 \times 10^{-6} \\
0 & -2.1687 \times 10^{-6} & 1.0000 \times 10^{-6} \\
0 & 2.0000 \times 10^{-6} & -1.0000 \times 10^{-6}
\end{array}\right], B=\left[\begin{array}{c}
0.0043 \\
0.0018 \\
0
\end{array}\right]
$$

So the matrix $M_{c}$ is

$$
M_{c}=\left[\begin{array}{ccc}
0.0043 & 9.5005 \times 10^{-9} & -2.9366 \times 10^{-14} \\
0.0018 & -4.0662 \times 10^{-9} & 1.2568 \times 10^{-14} \\
0 & 3.7498 \times 10^{-9} & -1.1882 \times 10^{-14}
\end{array}\right]
$$

By performing an elementary row operation (OBE) the matrix rank $M_{c}$ is equal to its dimension, i.e. 3. Based on control theory [9], the system above is a controlled system.

\subsubsection{Analysis of Observability System}

Definition 2 [9] When any initial state $x(0)=x_{0}$ singularly observable from any measurement of the system output of time $t=0$ to $t=t_{1}$, then the system is said to be "observed".

Sufficient and necessary conditions for a linear system to be observed, is that the matrix

$$
M_{0}=\left[\begin{array}{c}
C \\
C A \\
C A^{2} \\
\vdots \\
C A^{n-1}
\end{array}\right]
$$


have a rank equal to $n$.

Where matrix $\mathrm{C}$ is the system to know the result. Because it assumes that the output value is a variable $C_{s}, C_{p}$ and $C_{l}$ then the matrix is obtained $\mathrm{C}$ :

$$
C=\left[\begin{array}{lll}
1 & 0 & 0 \\
0 & 1 & 0 \\
0 & 0 & 1
\end{array}\right]
$$

By applying elementary row operations (OBE), rank $M_{p}=3$. Based on the observational theorem [9], the system is observed.

\section{Discussion}

This chapter describes the optimal control using Linear Quadratic Regulator (LQR), which then be simulated using MATLAB software.

\subsection{Optimal Control using LQR}

The LQR method is a modern control technique implemented in the form of space and time (state space) to design optimal dynamic regulators [10]. Basically, LQR is used to minimise the performance index equation or objective function

$$
J=\int_{t_{0}}^{t_{f}} 0.95 C_{s}^{2}+0.95 C_{p}^{2}+0.95 C_{l}^{2}+V^{2} d t .
$$

The LQR described is the design for the control system with an infinite span of time in which $t_{f}$ is the final time of control, $Q_{c}$ is a symmetric, semi-definite and positive matrix $R_{c}$ is a symmetric matrix, positive definite, and $u$ is a control vector. The steps are as follows:

1. Determining the value $R_{c}$ and $Q_{c}$.

2. Looking for a value of $P_{c}$, used toolbox MATLAB.

3. Looking for a gain value $K_{c}$.

4. Simulating the system with MATLAB simulink

5. Characteristic analysis to obtain the optimal system, i.e the fastest stable time and maximum results.

From some research using LQR method, the values of $Q_{c}$ and $R_{c}$ are determined by way of trial and error. The values of $Q_{c}$ and $R_{c}$ which gives optimal system are as follows:

$$
Q_{c}=\left[\begin{array}{ccc}
0.001 & 0 & 0 \\
0 & 0.001 & 0 \\
0 & 0 & 0.001
\end{array}\right]
$$


and $R_{c}=[1]$, using riccati algebra algorithm MATLAB, it is obtained

$$
P_{c}=\left[\begin{array}{ccc}
0.2757 \times 10^{3} & -0.6264 \times 10^{3} & -1.2592 \times 10^{3} \\
-0.6264 \times 10^{3} & 1.4655 \times 10^{3} & 2.9379 \times 10^{3} \\
-1.2592 \times 10^{3} & 2.9379 \times 10^{3} & 6.3760 \times 10^{3}
\end{array}\right] .
$$

So, the regulator gain value is $K_{c}=\left[\begin{array}{lll}0.0316 & 0.0074 & -0.0003\end{array}\right]$. In this simulation, optimal control on the concentration of lipids is expected to produce maximum lipid extraction. The input parameter values from Table 3 , for the initial condition are [7] $C_{s}=0.5, C_{p},=0.3$ and $C_{l}=0.1$.

\subsection{Optimal Control using PMP}

In this study the goal of optimal control completion is to optimize lipid concentration in microalgae particles by controlling the volume. From Equations (1), (2) dan (3), optimal controlwas identified using the maximum principle of Pontryagin. The steps are:

1. Form purpose function: The aim of this study to maximise lipid concentration of the solvent flow $\left(C_{s}\right)$ and lipid concentration in microalgae particles $\left(C_{p}\right)$ by minimising the volume of solvent $(V)$ inserted. From this problem, the purpose function is

$$
J(V)=\int_{t_{0}}^{t_{f}}\left(C_{s}(t)+C_{p}(t)-\frac{Q}{2} V^{2}(t)\right) d t
$$

2. Settlement Steps: Form the Hamilton function

$$
\begin{gathered}
H\left(C_{s}, C_{p}, C_{l}, V, \lambda\right)=C_{s}(t)+C_{p}(t)-\frac{Q}{2} V^{2}(t)+\sum_{i=1}^{3} \lambda_{i} f_{i} \\
H=C_{s}(t)+C_{p}(t)-\frac{Q}{2} V^{2}(t)+\lambda_{1}\left(\frac{-\left(1-\varepsilon_{p}\right)}{\varepsilon}\left(\frac{-k_{f} a\left(C_{p}-C_{s} a t^{*}\right)}{V\left(1-\varepsilon_{p}\right)}-k_{a} C_{p}+k_{d} C_{l}\right)\right) \\
-\lambda_{1} C_{s} \frac{S}{\rho \varepsilon V}+\lambda_{2} k_{d} C_{l}-\lambda_{2} k_{a} C_{p}-\lambda_{2} \frac{-k_{f} a\left(C_{p}-C_{s} a t^{*}\right)}{V\left(1-\varepsilon_{p}\right)}+\lambda_{3} k_{a} C_{p}-\lambda_{3} k_{d} C_{l}
\end{gathered}
$$

Maximize $H$ against vector control $v(t)$

$$
\begin{aligned}
\frac{\partial H}{\partial V} & =0 \\
V(t) & =\left(\frac{\lambda_{1} \frac{-k_{f} a\left(C_{p}-C_{s} a t^{*}\right)}{\varepsilon}-\lambda_{1} C_{s} \frac{S}{\rho \varepsilon}-\lambda_{2} \frac{-k_{f} a\left(C_{p}-C_{s} a t^{*}\right)}{\left(1-\varepsilon_{p}\right)}}{Q}\right)^{1 / 3}
\end{aligned}
$$


where, $v(t)=\min \left(9 \times 10^{-5}, \max (0, v)\right)$.

Determining the optimal $H^{*}$

$$
\begin{aligned}
H^{*}= & C_{s}(t)+C_{p}(t)-\frac{Q}{2} \min \left(9 \times 10^{-5}, \max (0, v)\right)^{2}(t)+\lambda_{1}\left(\frac{-\left(1-\varepsilon_{p}\right)}{\varepsilon}\right. \\
& \left.\left(\frac{-k_{f} a\left(C_{p}-C_{s} a t^{*}\right)}{\min \left(9 \times 10^{-5}, \max (0, v)\right)\left(1-\varepsilon_{p}\right)}-k_{a} C_{p}+k_{d} C_{l}\right)\right)-\lambda_{1} C_{s} \\
& \frac{S}{\rho \varepsilon \min \left(9 \times 10^{-5}, \max (0, v)\right)}+\lambda_{2} k_{d} C_{l}-\lambda_{2} k_{a} C_{p}- \\
& \lambda_{2} \frac{-k_{f} a\left(C_{p}-C_{s} a t^{*}\right)}{\min \left(9 \times 10^{-5}, \max (0, v)\right)\left(1-\varepsilon_{p}\right)}+\lambda_{3} k_{a} C_{p}-\lambda_{3} k_{d} C_{l}
\end{aligned}
$$

Solve the state and costate equations to obtain the optimal system.

State Equations:

$$
\begin{aligned}
\frac{\partial H^{*}}{\partial \lambda_{1}}= & \left(\frac{-\left(1-\varepsilon_{p}\right)}{\varepsilon}\left(\frac{-k_{f} a\left(C_{p}-C_{s} a t^{*}\right)}{\min \left(9 \times 10^{-5}, \max (0, v)\right)\left(1-\varepsilon_{p}\right)}-k_{a} C_{p}+k_{d} C_{l}\right)\right)- \\
& C_{s} \frac{S}{\rho \varepsilon \min \left(9 \times 10^{-5}, \max (0, v)\right)}, \\
\frac{\partial H^{*}}{\partial \lambda_{2}}= & k_{d} C_{l}-k_{a} C_{p}-\frac{-k_{f} a\left(C_{p}-C_{s} a t^{*}\right)}{\min \left(9 \times 10^{-5}, \max (0, v)\right)\left(1-\varepsilon_{p}\right)}, \\
\frac{\partial H^{*}}{\partial \lambda_{3}}= & k a C_{p}-k_{d} C_{l} .
\end{aligned}
$$

Costate Equations:

$$
\begin{aligned}
\frac{\partial \lambda_{1}}{\partial t}= & -\frac{\partial H^{*}}{\partial C_{s}}=-\left(1-\lambda_{1} \frac{S}{\rho \varepsilon \min \left(9 \times 10^{-5}, \max (0, v)\right)}\right), \\
\frac{\partial \lambda_{2}}{\partial t}= & -\frac{\partial H^{*}}{\partial C_{p}} \\
= & -\left(1-\lambda_{2} k_{a}-\lambda_{2} \frac{k_{f} a}{\min \left(9 \times 10^{-5}, \max (0, v)\right)\left(1-\varepsilon_{p}\right)}+\right. \\
& \left.\lambda_{1}\left(-\frac{\left(1-\varepsilon_{p}\right)}{\varepsilon}\left(\frac{-k_{f} a}{\min \left(9 \times 10^{-5}, \max (0, v)\right)\left(1-\varepsilon_{p}\right)}-k_{a}\right)\right)+\lambda_{3} k_{a}\right), \\
\frac{\partial \lambda_{3}}{\partial t}= & -\frac{\partial H^{*}}{\partial C_{l}}=-\left(\lambda_{1}\left(-\frac{\left(1-\varepsilon_{p}\right)}{\varepsilon} k_{d}\right)+\lambda_{2} k_{d}-\lambda_{3} k_{d}\right) .
\end{aligned}
$$

\section{Simulation}

\subsection{Using LQR Method}

Figure 1 shows after the optimal control has increased. Without controlling at $t=1800$ the value of lipid concentration in solvent flow $\left(C_{s}\right)$ remains $0.502 \mathrm{~kg} / \mathrm{m}^{3}$. After control, at $t=1800$ the value of lipid concentration in solvent flow $\left(C_{s}\right)$ amount $7.2785 \mathrm{~kg} / \mathrm{m}^{3}$. This indicates that the existence of the optimal control can affect lipid concentration in the solvent flow. Figure 2 


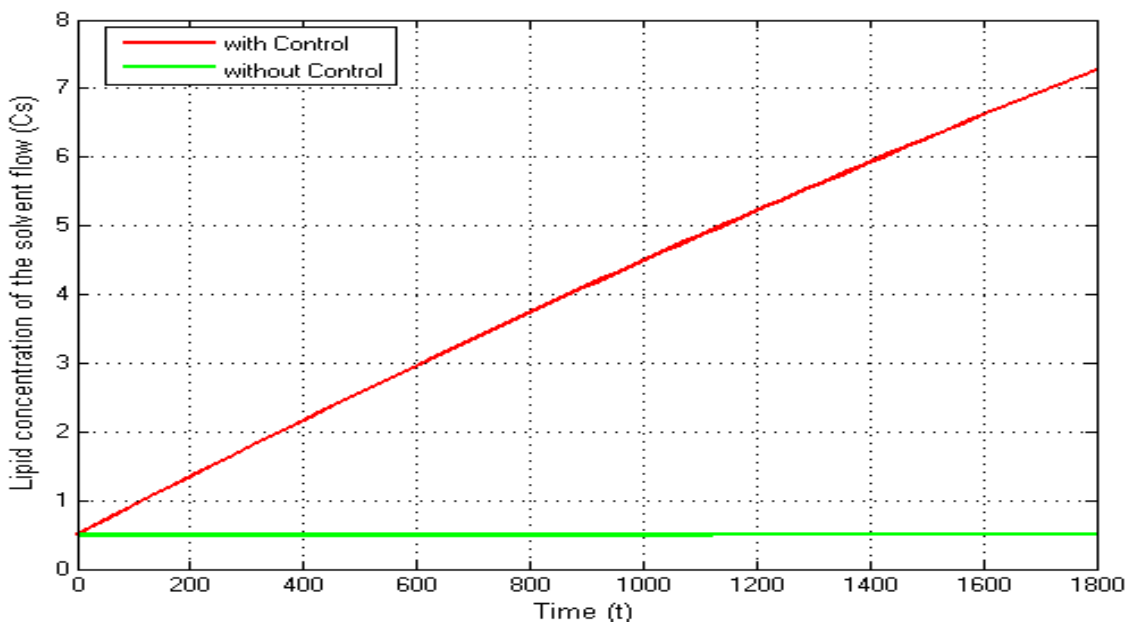

Figure 1: The Lipid Concentration of the Solvent Flow $\left(C_{s}\right)$

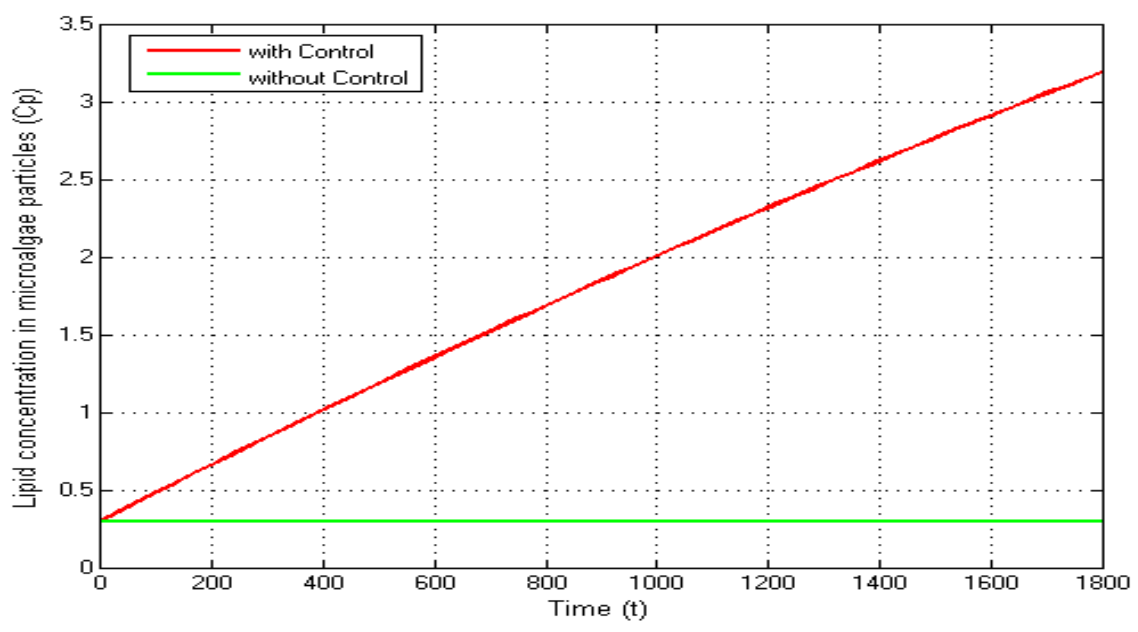

Figure 2: Lipid Concentration in Microalgae Particles $\left(C_{p}\right)$ 
shows after the optimal control has increased. Before controlling at $t=1800$ the value of lipid concentration in microalgae particles $\left(C_{p}\right)$ was initially $0.299 \mathrm{~kg} / \mathrm{m}^{3}$. Then after controlling at $t=1800$ the value of lipid concentration in microalgae particles $\left(C_{p}\right)$ get the final value 3.1913 $\mathrm{kg} / \mathrm{m}^{3}$.

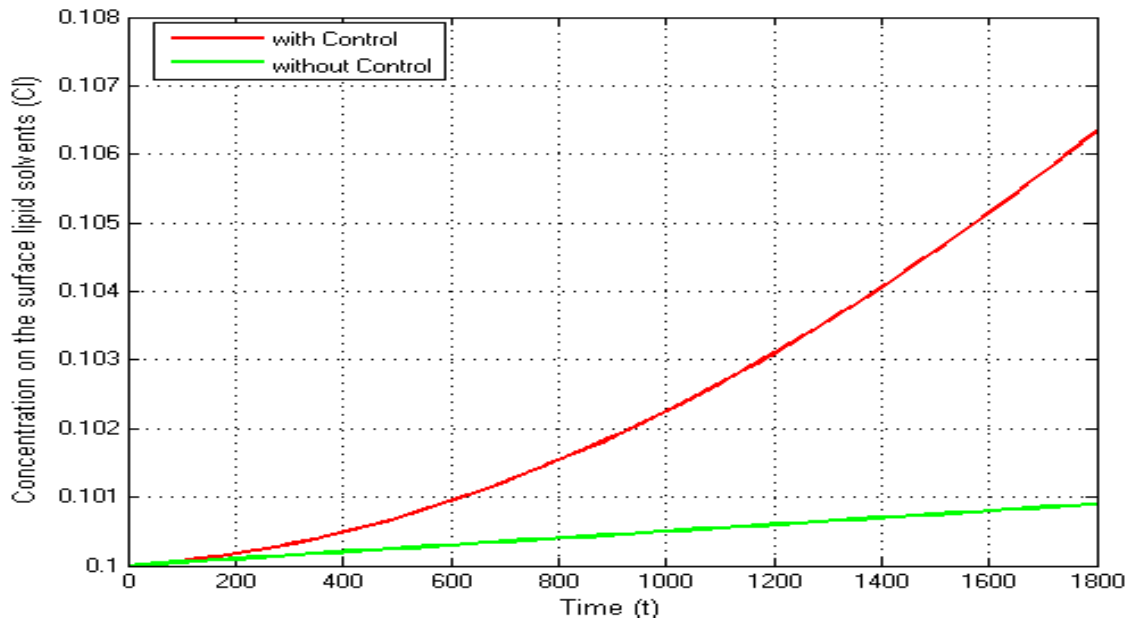

Figure 3: Concentration on the Surface Lipid Solvents $\left(C_{l}\right)$

Figure 3 shows after the optimal control has improved. Before controlling at $t=1800$ the value of Concentration on the surface lipid solvents $\left(C_{l}\right)$ was initially $0.1009 \mathrm{~kg} / \mathrm{m}^{3}$, then after control at $t=1800$ the value of Concentration on the surface lipid solvents $\left(C_{l}\right)$ was 0.1063 $\mathrm{kg} / \mathrm{m}^{3}$.

\subsection{Using PMP Method}

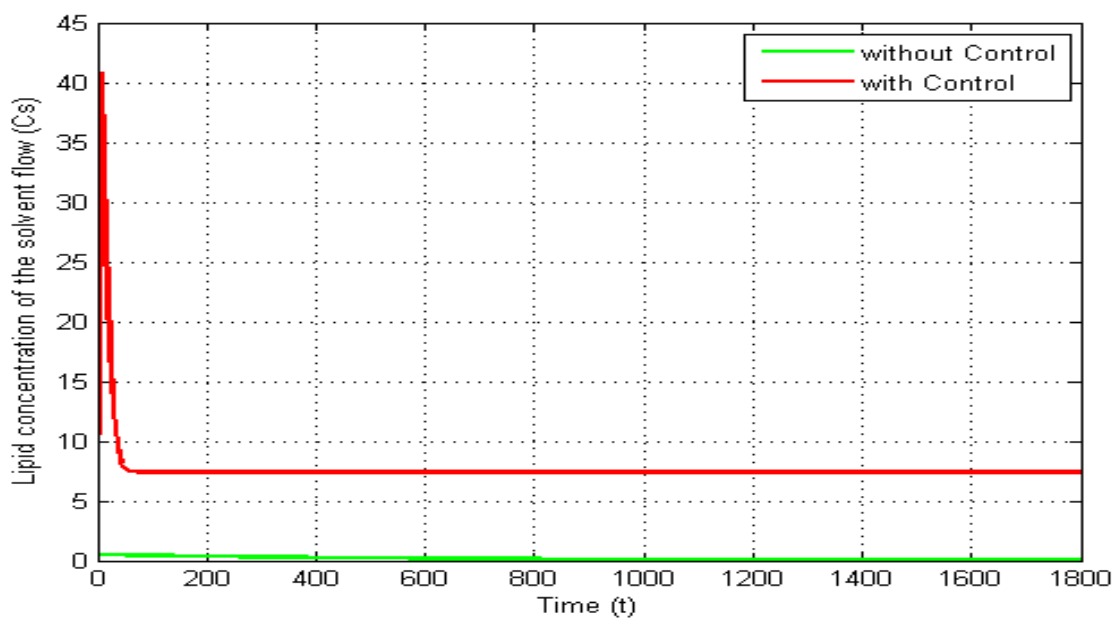

Figure 4: Lipid Concentration of the Solvent Flow $\left(C_{s}\right)$

Figure 4 shows after the optimal control has increased. Before controlling at $t=1800$ the value of lipid concentration in solvent flow $\left(C_{s}\right)$ was headed to $0 \mathrm{~kg} / \mathrm{m}^{3}$, then after control 
at $t=1800$ the value of lipid concentration in solvent flow $\left(C_{s}\right)$ amount $7.4138 \mathrm{~kg} / \mathrm{m}^{3}$. This indicates that after the existence of the optimal control can affect lipid concentration in the solvent flow.

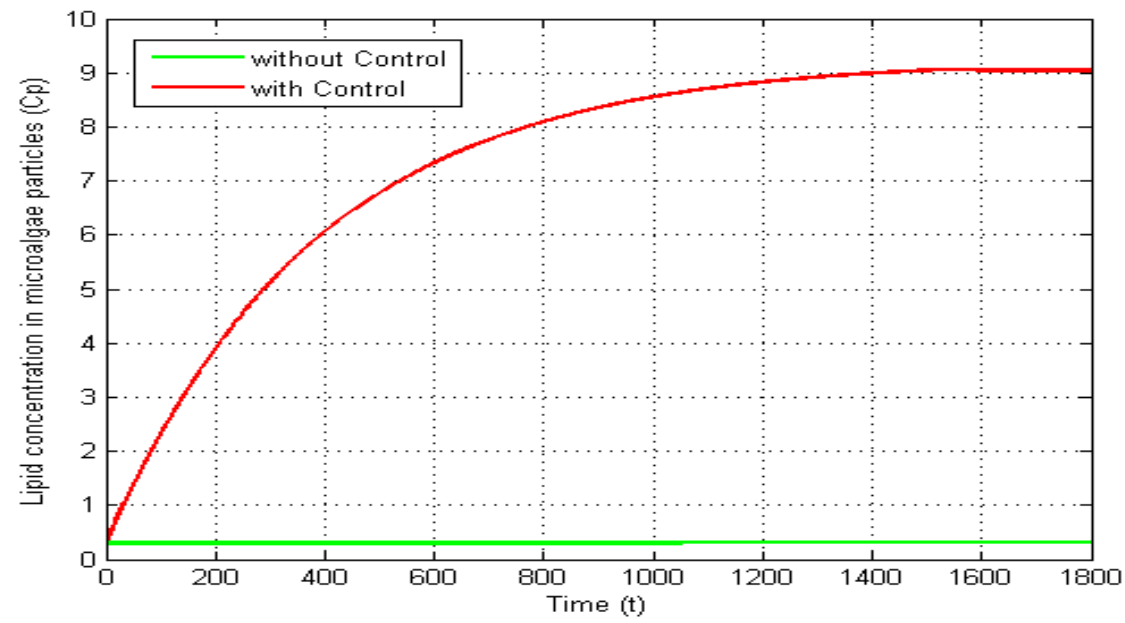

Figure 5: Lipid Concentration in Microalgae Particles $\left(C_{p}\right)$

Figure 5 , before controlling at $t=1800$, the value of lipid concentration in microalgae particles $\left(C_{p}\right)$ was $0.3046 \mathrm{~kg} / \mathrm{m}^{3}$. Then after given of optimal control at $t=1800$ the value of lipid concentration in microalgae particles $\left(C_{p}\right)$ get the final value is $9.0401 \mathrm{~kg} / \mathrm{m}^{3}$. This is shows that after given of optimal control to the lipid concentration in microalgae particles has the difference is quite significant.

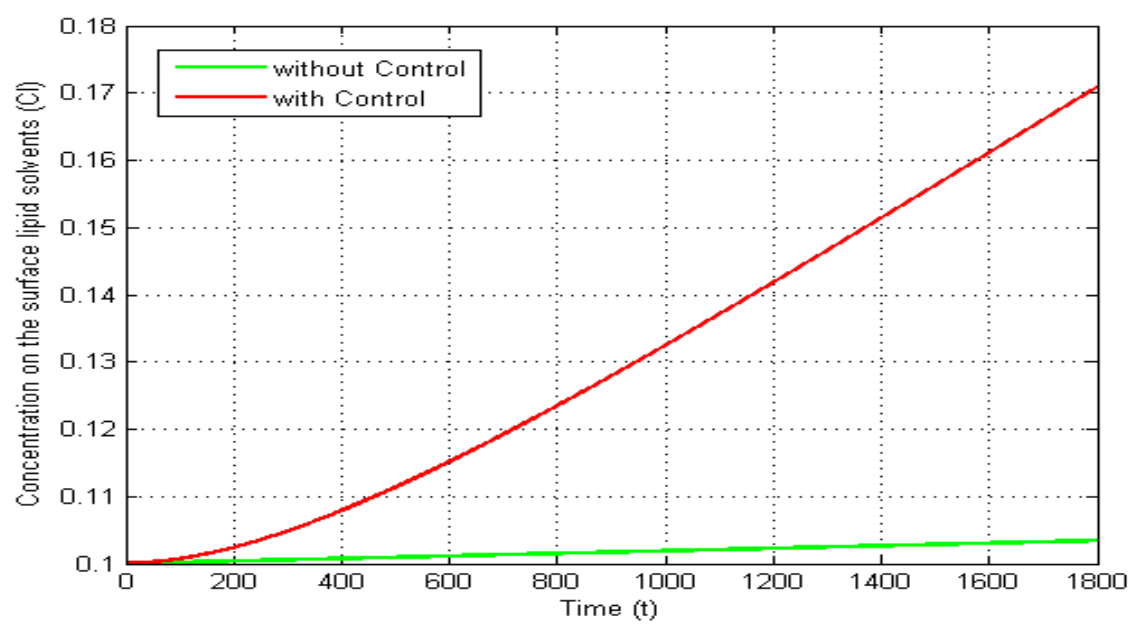

Figure 6: Lipid Concentration on the Surface Lipid Solvents $\left(C_{l}\right)$

Figure 6 , shows after the optimal control has increased. Before controlling $t=1800$, the value of concentration on the surface lipid solvents $\left(C_{l}\right)$ was $0.1009 \mathrm{~kg} / \mathrm{m}^{3}$, then after control at $t=1800$ the value of concentration on the surface lipid solvents $\left(C_{l}\right)$ was $0.1709 \mathrm{~kg} / \mathrm{m}^{3}$. This 
suggests that after optimal control can affect the concentration on the surface lipid solvents.

\section{Conclusion}

By using the LQR method, at the time of $t=1800 \mathrm{~s}$ it was found that, without the control, the concentration of lipids in the solvent stream $\left(C_{s}\right)$ was $0.502 \mathrm{~kg} / \mathrm{m}^{3}$. After control, the value increased to $7.2785 \mathrm{~kg} / \mathrm{m}^{3}$. For the value of lipid concentration in microalgae particles $\left(C_{p}\right)$ before being given optimal control is $0.299 \mathrm{~kg} / \mathrm{m}^{3}$ and after giving optimal control the value of lipid concentration in microalgae particles $\left(C_{p}\right)$ increased to $3.1913 \mathrm{~kg} / \mathrm{m}^{3}$. Then for the lipid concentration value on the surface of the particle $\left(C_{l}\right)$ before the control is $0.1009 \mathrm{~kg} / \mathrm{m}^{3}$ while after the control is done it becomes $0.1063 \mathrm{~kg} / \mathrm{m}^{3}$. For the PMP method at the same time $t=1800 \mathrm{~s}$ obtained that, before controlling the lipid concentration value in the solvent stream of $\left(C_{s}\right)$ to $0 \mathrm{~kg} / \mathrm{m}^{3}$, then increasing to $7.4138 \mathrm{~kg} / \mathrm{m}^{3}$. Furthermore, the initial condition of the value of lipid concentration in microalgae particles $\left(C_{p}\right)$ is $0.3046 \mathrm{~kg} / \mathrm{m}^{3}$ then after given optimal control the value of lipid concentration in microalgae particles $\left(C_{p}\right)$ increases to 9.0401 $\mathrm{kg} / \mathrm{m}^{3}$ and for the lipid concentration value on the surface of the particle $\left(C_{l}\right)$ before the control is $0.1009 \mathrm{~kg} / \mathrm{m}^{3}$, then after the control becomes $0.1709 \mathrm{~kg} / \mathrm{m}^{3}$.

So from the two methods used in the system, it is found that the PMP method shows the results obtained are more optimal than the results obtained using the LQR method.

\section{References}

[1] Rachmaniah, O., Elfera, Y. and Danang, H. Algae spirulina sp. oil extraction method using the osmotic and percolation and the effect on extractable components. Jurnal Teknik Kimia. 2010. 4(2): 287-294.

[2] Dyah, P. Produksi Biodiesel dari Mikroalga Chlorella sp dengan Metode Esterifikasi In-Situ. Ph.D. Thesis. Universitas Diponegoro. 2011.

[3] Mardlijah, Riyantoko, P. A., Sanjaya, S. and Hanafi, L. Optimal control of neutral lipids in microalgae production with nutrient limitation. MATTER: International Journal of Science and Technology. 2018. 4(1): 61-72.

[4] Mardlijah, Jamil, A., Hanafi, L. and Sanjaya, S. Optimal control of algae growth by controlling co 2 and nutrition flow using pontryagin maximum principle. Journal of Physics: Conference Series. 2017. 890(1): 012042.

[5] Izzati, N. and Mardlijah. Optimal feeding strategy on microalgae growth in fed-batch bioreactor model. International Journal of Computing Science and Applied Mathematics. 2015. 1(1): 1-5.

[6] Oktavianti, N. D. Kendali Optimal Pertumbuhan Mikroalga Melalui Tingkat Pengenceran Nutrisi. 2016.

[7] Siahaan, S. M. Pemodelan Perpindahan Massa Pada Ekstraksi Lipid Kontinu Mikroalga Chlorella Vulgaris Dengan Pelarut Cxm (CO2-Expanded Methanol). Ph.D. Thesis. Institut Teknologi Sepuluh Nopember. 2016. 
[8] Yang, Y.-H., Klinthong, W. and Tan, C.-S. Optimization of continuous lipid extraction from chlorella vulgaris by co2-expanded methanol for biodiesel production. Bioresource technology. 2015. 198: 550-556.

[9] Subiono. Matematika Sistem. Surabaya: Matematika ITS. 2003.

[10] Naidu, D. S. Optimal Control Systems. United States: CRC Press. 2002. 